\title{
Production Indicators of Mathematics Teachers in Public Universities of the Valencian Community on Web of Science
}

\author{
G. Lorenzo, M. Santagueda*
}

Department of Education, Jaume I University, Spain

Copyright (C) 2016 by authors, all rights reserved. Authors agree that this article remains permanently open access under the terms of the Creative Commons Attribution License 4.0 International License

\begin{abstract}
The current evaluation and comparison system of scientific production by impact factor has been criticised from different perspectives in recent years, and has ensured that publishing in high-impact journals does not necessarily imply that works are quality works. Many of these jobs are mostly not cited or, in the best of cases, only a very small number are, especially during the first years since their publication $[4,21]$. In this context, the h-Index appeared in 2005 [19], and is currently one of the most bibliometric indicators used to estimate the success of research work and to predict the impact of future production. Following that proposed in [11], we used the h-index as a measure of scientific quality and productivity of mathematics teachers in Public Universities of the Valencian Community on the Web of Science. The results showed that the h-Index widely correlates citations and number of items.
\end{abstract}

Keywords h-index, Mathematical Education, Productivity

\section{Introduction}

Scientific research has greatly influenced the economic and social development of countries. In recent years, resources have declined with the global economic crisis, and the need to evaluate scientific activity and productivity has emerged, which is one of the most direct criteria in the scientific literature $[9,21,7,8]$. We believe that scientific productivity evaluations are a necessary exercise because, in this way, researchers and universities can receive certain benefits through assessments made by institutional bodies (in Spain, Agencia Nacional de Evaluacin y Prospectiva ANEP, Comisin Nacional Evaluadora de la Actividad InvestigadoraCNEAI o Agencia Nacional de Evaluacin de la Calidad y Acreditacin, ANECA). The two main criteria used in Spain are, apart from the number of articles published (standard production) in the journals indexed on the (ISI) Web of Knowledge, the number of citations that the research has received and the impact factor of the journal that has published the research work (quality criterion)[21]. This evaluation and comparison system of scientific production by impact factor has been insistently criticised as publishing in high-impact journals does not necessarily imply that such works are quality works, and many of those jobs are mostly not cited or, in the best of cases, only a very small number are, especially during the first years since their publication $[4,6,13,21,17]$. A quite different work appeared half way through 2005, and was baptised by a physics teacher at the University of California, San Diego, as the h-index [11]. The idea is extremely simple. Each work by a given author is collected and sorted into descending order based on the citations received. Therefore, each work occupies a position in a ranking according to the number of citations that it receives, called a range, along with citations. Thus two lists of numbers are created, an upward one (ranges) and a downward (citations) one. Where both values cross, we obtain the h-index, a measure of position, namely one in which the volume of citations is less than or equals the number of ordered items that occupies the downward distribution of citations [10]. Notwithstanding, it is true that a scientists h-index can never diminish over time [10]. According to Braun, Glnzel and Schubert [3], among the advantages that the h-index offers we find: (a) it is robust; that is, it is insensitive to any accidental excess from unmentioned works, and also to one or more extraordinarily cited works; (b) it combines the effect of "quantity" (number of publications) and "quality" (citation rate) in a balanced and targeted manner; and (c) it can be calculated for specific periods, and not just for a lifetime. As far as we know, the h-index in the Mathematical Education area has never been studied in Spain. Therefore, the objectives of this study were to: present the h-index of the full-time teachers in different public universities in the Valencian Community (east Spain) in this knowledge area; examine the statistical distribution of this index in this population, and see where the proportionality constant is located; consider the relationship between the h-index and other popular measures used in Spain to evaluate research productivity; e.g. number of articles and citation index; compare the two areas of expertise to the journals that publish, the mean of authors per article and evolution on the ISI Web of Knowledge. 


\section{Method}

\subsection{Design}

This is a descriptive, comparative and correlational study of document analyses. It took into account the considerations proposed by Hirsch [11], the considerations made by Hernandez et al. [19], Ramos-Alvarez et al. (2008), the recommendations in the Principles of Berlin for Rankings of Institutions of Higher Education [12] and the study of Olives-Avila and Musi-Lettuce [15].

\subsection{Participants}

The sample consisted in 19 full-time university teachers (assistant doctors, university holders, contracted doctors, college and university professorrs) who belong to the mathematical education area in several universities in the Valencian Community (east Spain)

\subsection{Materials}

a) Websites of the departments in the Mathematical Education Area b) The (ISI) Web of Knowledge Database. This is available on the platform (ISI) Web of Knowledge and contains information about multidisciplinary research in journals for which their impact factor is calculated.

\subsection{Procedure}

Firstly, participants were selected from the information that appeared on the websites of the Mathematical Education Departments in Spain. Secondly, data were obtained according to the records collected on the (ISI) Web of Knowledge. We had to bear in mind that there were mistakes in many the names of authors (example: Author $=($ Gonzalez, LuisMillan $)$ AND Address $=($ Univ Valencia $) /$ Author $=($ Gonzalez, LM or Author = (Casajus, Jose A.) AND Author = (Casajus, JA)). It was found that the same author and the same cited work had been collected with different names. For a more detailed review of the process, it is worth referring to the study of Osca-Lluch, Civera and Pearanda [16], where possible variations are mentioned in the names of teachers affiliate institutions. Others tended to attach their names by a script, so this was also taken into account in the search. The data collection process was performed in the above database by entering the section "General Search", where the fields "Author" and "Address" were used, and the "Topic" field was even used in some cases. One surname, or both surnames as in Spain, were always inputted, and sometimes with a capital letter, other times in the lower case, and at times followed by a space and the initials of the authors name. Wildcards and Boolean operators were also used to ensure the delivery of all items by authors in order to consider all the possible combinations: the initial(s) of the first name(s) and the initial of the first surname, followed in all cases by the name supplied by the official university websites.

\subsection{Method to calculate the $\mathrm{H}$-index}

The method to calculate the h-index that Hirsch suggested [11], which was described in more detail by Imperial and Rodriguez-Navarro [20], consists in the following steps: logging into the Web of Knowledge, choosing the "General
Search" option, and keying in the authors name in the corresponding window. Currently after having sought the author, the (ISI) Web of Knowledge allows us to immediately calculate the h-index, create a report of citations, and the following items are obtained almost instantaneously: total times cited, total times quoted without self-citations, articles cited in, total articles without self-citations, average citations per element and h-index.

\subsection{Total number of citations and maximum citation}

The total number of citations is the sum of all the citations of a researchers work in the aforementioned database. Maximum citation is a work that has been cited the most among the works of a given author.

Searches were made from October 2015 to November 2015. Finally, we ought to consider that there could be some variations when viewing the results in this study. This is mainly because the database (ISI) Web of Knowledge does not report monthly reports with static results, but is instead characterised as being dynamic as information is constantly being added. Hence the number of records may vary from day to day.

\section{Results and data analysis}

We studied 19 teachers. We considered those who occupied full-time posts in any public Valencian university and in the Mathematical Education area. Of these, 17 had publications on the Web of Knowledge (89.5\%).

\section{1 h-index for each teacher}

Figure 1 shows a chart used to visualise the two different h-indices considered for all the 19 Mathematical Education teachers. We can see that almost all of them had a general hindex of their publications, which was higher than or equalled that which corresponded to Mathematical Education. This indicates that some started out in some mathematics branch other than Mathematical Education. The mean h-index in Mathematical Education in the Valencian Community was 0.68 .

\section{Mathematical Education (ME)}

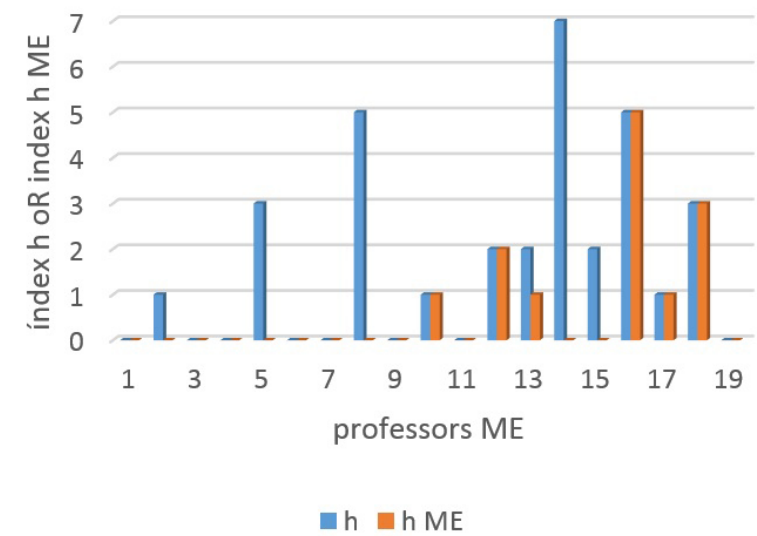

Figure 1. Comparison between the general h-index and that corresponding to Mathematical Education of the studied teachers. 


\subsection{Articles and $h$-index for each teacher.}

Figure 2 shows the relation between the number of articles published and the h-index. We stress that only two teachers had an h-index over 3 . The mean number of articles for each studied teacher was 6.4. However, it is necessary to point out that of the 114 articles found, 50 belonged to the two aforementioned teachers.

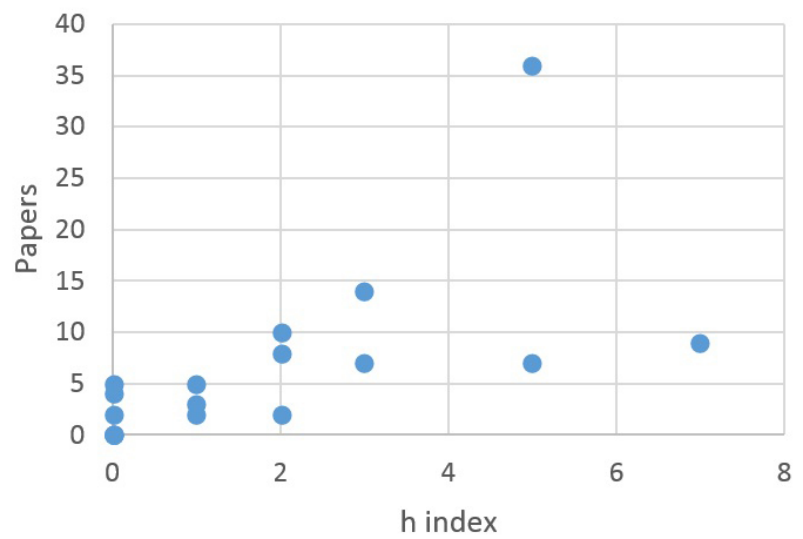

Figure 2. Comparison between the general h-index of the studied teachers and the number of published articles.

\subsection{Citations and h-index for each teacher.}

When we considered only citations in Mathematical Education, the rank of citations fell between 0 and 67 when considering the citations of any publication (Figure 3), and between 0 and 37 when not considering self-citations (Figure 4). The largest number of citations corresponded to the highest h-index in Mathematical Education.

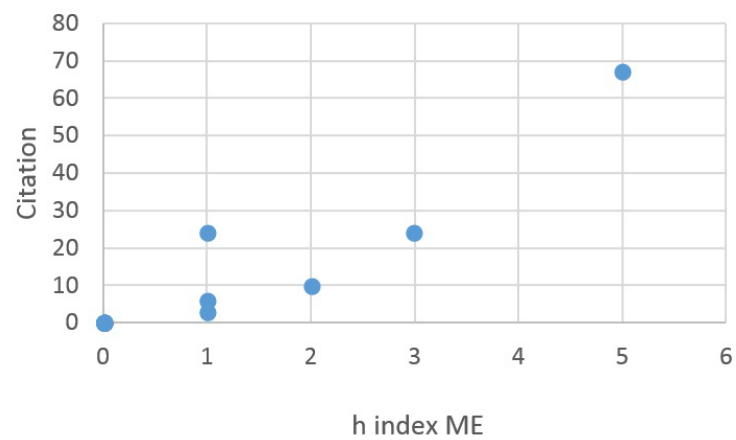

Figure 3. Comparison between the Mathematical Education h-index of the studied teachers and the number of citations that their articles had received.

Once again, $99 \%$ of the citations concentrated on four professors, of whom two were those previously mentioned.

\subsection{Analysis by Universities.}

The three studied universities with a Mathematical Education area present on their own website were the Universitat Jaume I of Castelln (UJI), the University of Valencia (UV) and the University of Alicante (UA). According to universities, the UV had higher h-indices than the other two (7), followed by the UA with a maximum of 5 (Figure 5). When we observed only the h-index that corresponded to Mathematical

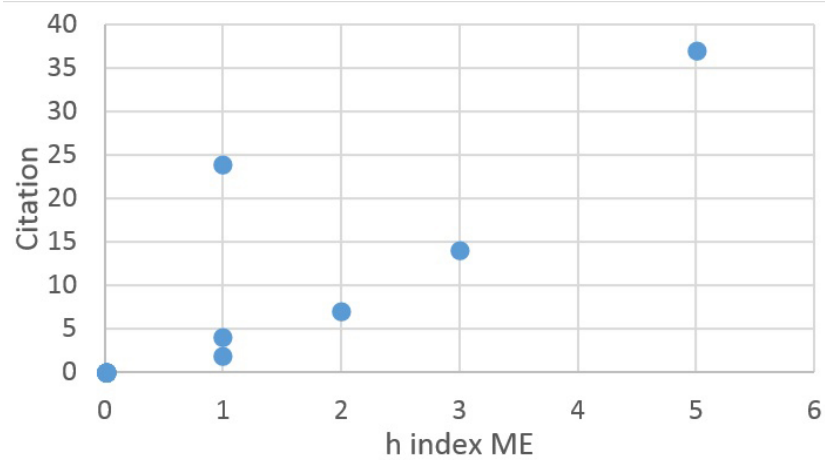

Figure 4. Comparison between the Mathematical Education h-index of the studied teachers and the number of citations (without self-citations) that their articles had received.

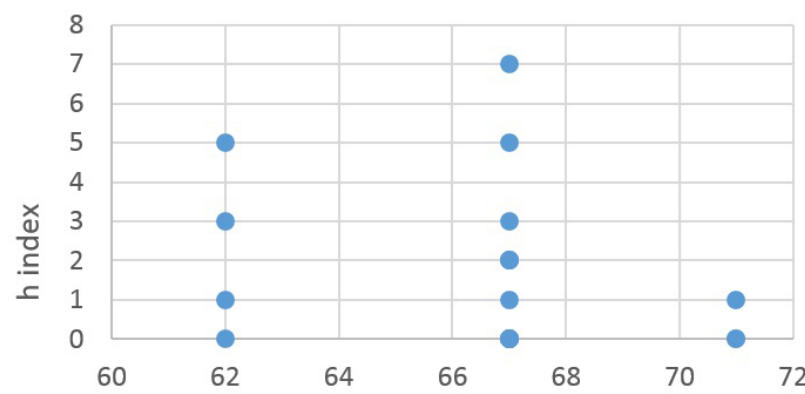

Universities: 62 UA, 67 UV, 71 UJ

Figure 5. Comparison between h-indices and the considered universities.

Education, the situation reversed (Figure 6): the UA had an index of 5, while the UV had one of 2 .

When we observed the articles that we found for each studied teacher, the UA excelled with 36 and 14 publications for two of its teachers, whereas the UV had a maximum of 10 publications for one of its teachers. In absolute values, we found 114 articles in the Valencian Community, 57 from the UV and 55 from the UA (Figure 7).

Finally, the citations received (after deleting self-citations) varied between 0 and 121 . Of the 336 citations we detected in the articles, 282 corresponded to the UV, whereas 53 were for the UA (Figure 8).

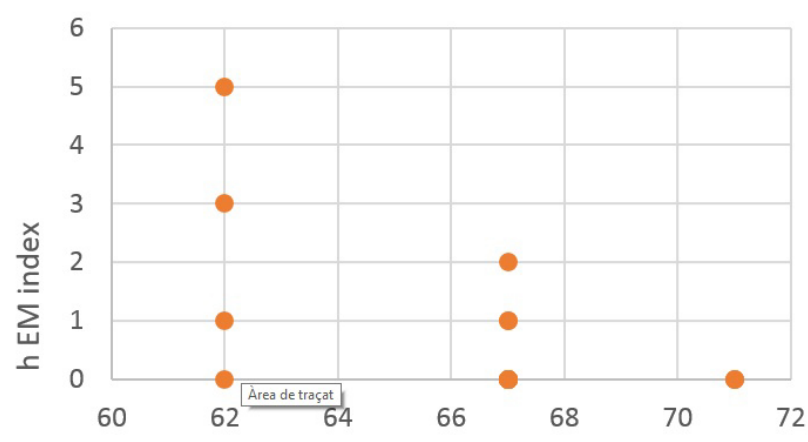

Universities: 62 UA, 67 UV, 71 UJ

Figure 6. Comparison between the Mathematical Education h-index and the considered universities. 


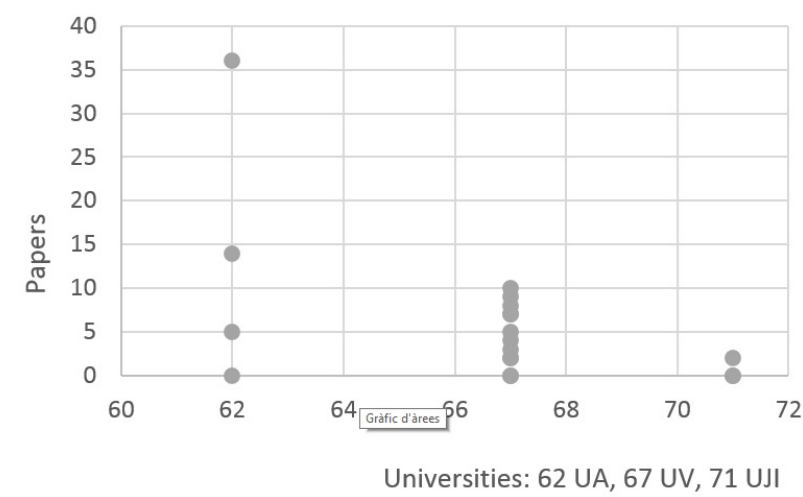

Figure 7. Comparison between the Mathematical Education h-index and the considered universities.

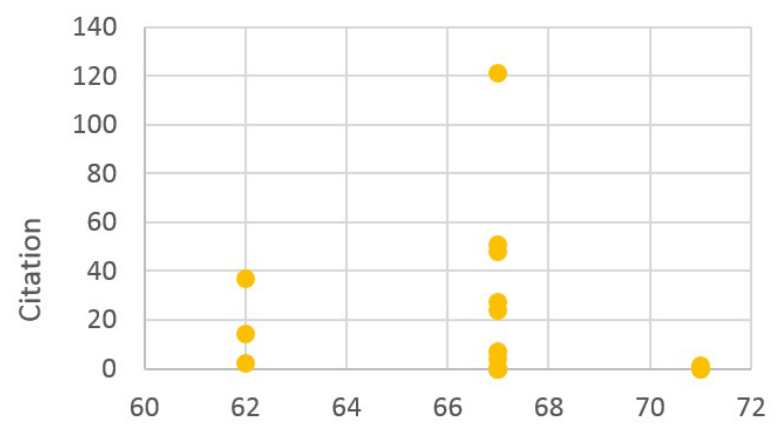

Universities: 62 UA, 67 UV, 71 UJ

Figure 8. Comparison of citations to the articles of the considered teachers and universities.

\section{Conclusions}

As far as we know, this is the first study into the h-index of scientific productions in the Mathematics Education area in Valencia (Spain). The interpretation of the presented data is qualified by the visibility, or not, of the teachers on the websites of their departments, and by their productivity on the Web of Knowledge. We realised that there could be other Mathematical Education teachers who have published, but their job is not full-time in the corresponding area, which makes them hard to find. Ball [2] stated that the procedures followed to select university teachers is sometimes dark and inbred. So the Hirsch method could be used to make decisions about promoting teachers or academic funding as it records all works in years. This study showed that two Valencian universities had more tradition in Mathematical Education, the Universities of of Valencia and Alicante, and in such a way that the careers of the teachers who made up the different departments did not generally start in Mathematical Education. We concluded that the h-index is a robust indicator of research quality. The indices that we found were relatively low. However, we must bear in mind that doctors in Mathematical Education in Valencia are relatively recent, and the evolution of their productivity and inclusion on the Web of Knowledge may have obeyed the policies of State Agency assessments as we realise that many publications are not reflected. Most of the articles that we found concentrated among a few teachers, thus efforts must be made to ensure that all the university teachers in Mathematical Education areas increase their productivity in this area. Something similar happens with citations, as numbers concentrate among a few people, and are acceptably high. All this has to be taken into account for the qualifications of teachers in these knowledge areas because, as their research career has been neither well established nor lasted many years, starting ones productivity in Mathematical Education is not easy. Therefore, we believe that this study is useful in many ways, some of which are: for teachers because they have a standard of comparison; for the various committees and commissions that evaluate teachers in this knowledge area; finally, this type of study allows those who legislate to adapt distinct levels of accreditations to different knowledge more realistically.

\section{Acknowledgements}

We are very grateful to experts for their appropriate and constructive suggestions to improve this template.

\section{REFERENCES}

[1] Agencia Nacional de Evaluación de la Calidad y Acreditacin (ANECA), Principios y orientaciones para la aplicación de los criterios de evaluación, Online available from http://webs.uvigo.es/es-ct/pep _nuevo_principiosyorientaciones.pdf

[2] P. Ball. An index for fair ranking of scientists. Nature, n. 436, p. $900,2005$.

[3] T. Braun, W. Glnzel, A. Schubert. A Hirsch-type index fort journals. The Scientist, n. 19, p. 22, 2005.

[4] G. Buela-Casal. Evaluacin de la calidad de los artculos y de las revistas cientficas: propuesta del factor de impacto ponderado y de un ndice de calidad. Psicothema, n. 15, p. 23-35, 2003.

[5] G. Buela-Casal et al. Ranking de 2009 en investigacin de las universidades pblicas espaolas. Psicothema, n. 22, p. 171-179, 2010.

[6] D. Colquhoun. Challenging the tyranny of impact factors. Nature, n. 423, p. 479, 2003.

[7] J. Devis et al. Disciplinas y temas de estudio en las ciencias de la actividad fsica y el deporte. Revista Internacional de Medicina y Ciencias de la Actividad Fsica y el Deporte, v. 10, n. 37, p. 150-166, 2010.

[8] P. Dorta-Gonzlez, M.I. Dorta-Gonzlez. Indicador bibliomtrico basado en el ndice h. Revista de Documentacin Cientfica, v. 33, n. 2, p. 225-245, 2010.

[9] M.A. Garca-Prez. Assessors odd listings dont inspire confidence.Nature, n. 406, p. 343, 2000.

[10] Grupo Scimago. El ndice h de Hirsch: aprotaciones a un debate. El professional de la informacin, v. 15, n. 4, p. 304-306, 2006. 
[11] J.E. Hirsch. An index to quantify an individuals scientific research output. Proceedings of the National Academy of Sciences of the U.S.A., n. 102, p. 16569-16572, 2005.

[12] International ranking expert group. Berlin principles on ranking of Higher Education Institutions, Online available from http://www.che.de/downloads/Berlin_Principles _IREG_534.pdf

[13] H.F. Moed. The impact-factors debate: the ISIs uses and limits. Nature, n. 415, p. 731-732, 2002.

[14] B. Musi-Lechuga et al. Produccin de los profesores funcionarios de psicologa en Espaa en artculos de revistas con factor de impacto de la Web of Science. Psicothema, n. 15, p. 539-548, 2005.

[15] J.A. Olivas-vila, B. Musi-Lechuga. Anlisis de la produccin de los profesores funcionarios de Psicologa en Espaa en artculos de revistas de la Web of Science. Psicothema, v. 22, n. 4, p. 909-916, 2010.

[16] J. Osca-Lluch,M.C. Civera, O.M. Pearanda. Consecuencias de los errores en las referencias bibliogrficas. El caso de la revista Psicothema. Psicothema, n. 21, p. 300-30, 2009.
[17] J. Reverter-Masia. Publicaciones cientficas y evaluacin de la vida profesional de un cientfico. Nutricin Hospitalaria, v. 27, n. 4, p. 1368-1369, 2012.

[18] J. Reverter-Masa, C. Jove-Deltell, G. Daza-Sobrino, V. Hernndez-Gonzlez. Las revistas espaolas de Ciencias de la Actividad Fsica y el Deporte: cmo elegir la revista donde publicar. Educatio siglo XXI, n. 30, p. 217-232, 2012.

[19] J. Reverter-Masa, C. Jove-Deltell, G. Daza-Sobrino, V. Hernndez-Gonzlez. Indicadores de produccin de los profesores de Educacin Fsica y Didctica de la Expresin Corporal en Espaa en la Web of Science. Perspectivas em Ciłncia da Informao, v.18, n.3, p.3-23, 2013.

[20] A. Rodrguez Navarro, J. Imperial Rdenas. ndice h. Gua Para la Evaluacin de la Investigacin Espaola en Ciencia y Tecnologa Utilizando el ndice h. Madrid: Consejera de Educacin de la Comunidad de Madrid, 2007.

[21] J.F. Salgado, D. Pez. La productividad cientfica y el ndice h de Hirchs [sic] de la psicologa social espaola: convergencia entre indicadores de productividad y comparacin con otras reas. Psicothema, n. 19, p. 179-189, 2007. 